\title{
Is mediolateral episiotomy angle associated with postpartum perineal pain in primiparous women?
}

\author{
(iD) Halenur Bozdag, ${ }^{1}$ (D) Esra Akdeniz, ${ }^{2}$ (D) Dondu Demirel Durukan, ${ }^{3}$ (D) Erol Arslan, ${ }^{4}$ (D) Meryem Hocaoglu ${ }^{1}$ \\ ${ }^{1}$ Department of Obstetrics and Gynecology, Istanbul Medeniyet University, Goztepe Training and Research Hospital, Istanbul, Turkey \\ ${ }^{2}$ Division of Biostatistics, Marmara University Faculty of Medicine, Istanbul, Turkey \\ ${ }^{3}$ Department of Obstetrics and Gynecology, Yedikule Surp Pirgic Armenian Hospital, Istanbul,Turkey \\ ${ }^{4}$ Department of Obstetrics and Gynecology, Cukurova University Faculty of Medicine, Adana, Turkey
}

\begin{abstract}
OBJECTIVE: Our aim is to elucidate the relationship between mediolateral episiotomy (MLE) angle and postpartum perineal pain.

METHODS: This study was designed prospectively. Primiparous women with MLE in the postpartum period were included in the study and divided into three groups according to episiotomy angle ranges (Group 1: $<40^{\circ}$, Group 2: $40^{\circ}-60^{\circ}$, and Group 3: $>60^{\circ}$ ). Postpartum perineal pain was quantified with the short-form McGill Pain questionnaire (SF-MPQ) consisting of the following three parts: Sensory-affective-verbal descriptions, visual pain scale (VPS), and present pain intensity scale (PPI). Postpartum perineal pain scores on days 1 and 7 were compared among the angle group.

RESULTS: Overall, 86 eligible women were enrolled in this study. Seventy-three women (85\%) scored the perineal pain between 0 and 3 on the VPS and 13 women (15\%) rated the pain from 4 to 6 on the $1^{\text {st }}$ postpartum day. No significant differences were noted among the three groups regarding the total pain scores on SF-MPQ and on the each part of form at the $1^{\text {st }}$ postpartum day. At 7 days postpartum, total pain score was found significantly high in Group 1 [Med; IQR (min-max)=0; 4 $(0-5)$ ] compared with Group 2 [Med; IQR ( $\min -\max )=0 ; 0(0-5)$ ]. The pain scores obtained from the sensory, affective, VPS, and PPI parts of the questionnaire were [Med; IQR (min-max) $=0 ; 1(0-2)$ ], [Med; IQR (min-max) $=0 ; 1(0-1)$ ], [Med; IQR $(\min -\max )=0 ; 2(0-2)]$, and [Med; IQR (min-max) $=0 ; 0.25(0-1)]$, respectively, in Group 1. For Group 2, pain scores obtained from the sensory, affective, and PPI were [Med; IQR (min-max) $=0 ; 0(0-1)$ ]; and VPS was [Med; IQR (min-max) $=0 ; 0(0-2)$ ]. No significant differences were observed between Groups 1 and 2 for each part of the questionnaire on day 7. Percentage of need for analgesics on day 7 was found significantly higher in Group 1 (42.9\%) than Group 2 (31.2\%)
\end{abstract}

CONCLUSION: MLE at an angle $<40^{\circ}$ to the midline is associated with a higher score of perineal pain and an increase need for analgesics during the early postpartum days.

Keywords: Incision angle; mediolateral episiotomy; pain relief method; postpartum perineal pain.

Cite this article as: Bozdag $H$, Akdeniz E, Demirel Durukan D, Arslan E, Hocaoglu M. Is mediolateral episiotomy angle associated with postpartum perineal pain in primiparous women? North Clin Istanb 2021;8(2):150-159.

$\mathrm{P}$ ostpartum period is important for maternal and neonatal surveillance. Adaptation of newborn this period depends on overall mother's wellbeing [1]. In this period, perineal pain obstructs mother's mobility in daily activities particularly breastfeeding period and disturbs her ability to care for her baby. Postpartum perineal pain has been reported with the range from $92 \%$ to $100 \%$ of all women. Bruising of perineum with spontaneous trauma or surgical

Received: February 29, 2020 Accepted: August 27, 2020 Online: March 05, 2021

Correspondence: Halenur BOZDAG, MD. Istanbul Medeniyet Universitesi, Goztepe Egitim ve Arastirma Hastanesi, Kadin Hastaliklari ve Dogum Klinigi, Istanbul, Turkey.

Tel: +90 5355909472 e-mail: halenurbozdag@hotmail.com

(c) Copyright 2021 by Istanbul Provincial Directorate of Health - Available online at www.northclinist.com 
incisions (i.e., episiotomies) are common causes of postpartum perineal pain [2]. Ninety-seven percent of women with episiotomy experienced perineal pain and it is much more intensive compared the pain of women with spontaneous perineal trauma [3]. Perineal pain related with episiotomy or perineal laceration has persisted in $10 \%$ of women [4]. Persistency of perineal pain might be cause of postpartum depression and impair women' life quality [5].

Episiotomy is a surgical incision of perineum to increase the size of the vaginal outlet to facilitate the baby's birth during the last part of the second stage of delivery [6]. There are at least seven types episiotomy described in the literature according to starting point and ending direction [7]. Among these episiotomy types, mediolateral episiotomy (MLE) has been widely preferred technic in several Asian countries beside European countries [8,9]. MLE technic is related to much more perineal pain than the other episiotomy types [10].

Postpartum perineal pain-management strategies are essential part of postpartum care. There are several pharmacological and non-pharmacological pain relief methods. The efficacy of these methods and comparison with each other has been investigated in managing acute postpartum perineal pain [11]. Cooling treatments, topical anesthetics, parenteral or oral analgesics, and nonsteroidal anti-inflammatory drugs (NSAIDs) are in the commonly reported $[12,13]$. NSAIDs and paracetamol have been associated with adverse cardiovascular, gastrointestinal, and renal side effects and are not completely benign [14]. For women with MLE, the other pain relief strategy may be to apply episiotomy with suitable angle to cause of the minimum perineal pain. To avoid from the angle related with perineal pain may reduce need to analgesic drugs and to prevent to pain chronicity.

In this study, we focused on the relation between the MLE angle and the perineal pain on day 1 and day 7 after birth. Our aim was to find the MLE angle related with the least or the most perineal pain.

\section{MATERIALS AND METHODS}

We performed a prospective observational cohort study over 6 consecutive months. The study was approved by Istanbul Medeniyet University Goztepe Training and Research Hospital Ethics Committee (20L2012).

The inclusion criteria of the study were as following: Primiparous women aged 18-35 years, at or more than 37 weeks gestation, vaginal delivery with MLE, and sin-

\section{Highlight key points}

- Mediolateral episiotomy with angle less than $40^{\circ}$ in primiparous women is associated with more perineal pain during the early postpartum period.

- Mediolateral episiotomy in the $40^{\circ}-60^{\circ}$ angle range may be pain relief strategy for creating comfortable condition and managing postpartum perineal pain.

gleton pregnancy with cephalic presentation. The exclusion criteria were as following: Pregnant women delivered instrumental delivery (with vacuum extraction and/ or forceps), multiparous women, multiple pregnancy, the presence of fetal presentation abnormality, having spontaneous perineal trauma (any degree), and hematoma formation related or not with episiotomy line.

At the beginning, power analysis was performed to calculate the numbers of patients needed for study. For an effect size of 0.35 , a significance level 0.05 and a power of 0.8 a total of 84 women were required for the study. This sample size was calculated using GPower 9.3 based on the ANOVA test for independent groups and assumed to preserve an overall alpha of 0.05 , considering three groups of episiotomy angles [15].

During the 6 months study period, 626 women gave birth vaginally at obstetric wards of Goztepe Research and Training Hospital and episiotomy was performed in $514(82 \%)$ of these women. MLE was performed in $238(96.3 \%)$ of 247 primiparous women. A total of 107 primiparous women with right-sided MLE were examined by two observers at the postpartum first 24 h. Eighty-six of them completed the pain questionnaire both on day 1 and day 7 .

All pregnant women were monitored in labor unit. When the cervix was fully dilated and satisfactory head descent was showed, they were transferred to the delivery room. MLE is defined as an incision beginning in the midline (Within $3 \mathrm{~mm}$ of the midline at the posterior fourchette) and directed laterally and downward away from the rectum with $40^{\circ}-60^{\circ}$ angle [7]. The episiotomy incision was performed using a pair of sharp episiotomy scissors after a local anesthetic agent $(10 \mathrm{~mL}$ of lidocaine $1 \%)$ was infiltrated into the skin and subcutaneous tissues and underlying perineal muscles along the episiotomy line. Head was delivered by Ritgen's maneuver. Active management of the third stage of labor was conducted three steps: (1) Administration of a uterotonic drug, (2) controlled cord traction, and (3) uterine massage after 
delivery of placenta. The episiotomy wound was repaired by traditional interrupted technique. The skin was repaired with interrupted transcutaneous stitches using $2 / 0$ slowly absorbable polyglactin 910 suture material.

All participants enrolled in the study were informed about the study. All women were examined by the clinical research fellows (HB, DD) after delivery at the first $24 \mathrm{~h}$. Measurements belong to episiotomy area were done with a flexible tape measure. Episiotomy distance was measured from the posterior fourchette to the lowest caudal tip of episiotomy (e). The distance of midline from the posterior fourchette to anal canal (a), the length of the perpendicularly line from the caudal tip of episiotomy to "a" line (b), and the distance from the caudal tip of episiotomy to anal canal (c) were measured in the lithotomy position. A triangle shape was obtained like previously defined [16]. All measurements were recorded at the form of each patient. The episiotomy angle was defined an angle between line " $a$ " and line " $e$ " and calculated from the equation with Sinus $\alpha$.

At first, all participants were examined in terms of perineal trauma and hematoma formation. Perineal pain was defined to them as a pain related with episiotomy line and not related abdominal pain cramping of uterus occurring breastfeeding or hemorrhoidal pain. Women were asked about perineal pain and pain interference with daily activities in the postpartum period at the first $24 \mathrm{~h}$ (in hospital) by face-to-face interview and by phone or face-to-face interview on day 7. Pain assessment was quantified with the short-form McGill Pain questionnaire (SF-MPQ). The questionnaire form consists of three parts: Sensory-affective-verbal descriptions, visual pain scale (VPS), and present pain intensity scale (PPI) [17]. The sensory pain scale of SF-MPQ has 11 items which takes values from 0 to 3 (in the range of painless to severe pain) and thus total ranges from 0 to 33 . The affective pain scale of SF-MPQ has 4 items with total ranges from 0 to 12 . The PPI scores range from 0 to 5 (0: no pain, 1 : mild; 2 : discomforting; 3 : distressing; 4 : horrible; and 5: excruciating pain) and the VPS scores range from 0 to $10[17,18]$.

Obstruction to activities of daily living was evaluated by questioning the patient about the presence of the perineal pain interfered with their ability to sit comfortably (yes/no), to move (yes/no), to defecate (yes/ no), and to sleep (yes/no). Postpartum analgesic use at the first $24 \mathrm{~h}$ was obtained by medical record and by self-reports on day 7 . The analgesics were grouped as oral paracetamol $(500 \mathrm{mg})$, intramuscular diclofenac sodium $(75 \mathrm{mg})$, or both.

Women who had perineal pain were grouped according to their episiotomy angle: Group $1\left(<40^{\circ}\right)$, Group $2\left(40-60^{\circ}\right)$, and Group $3\left(>60^{\circ}\right)$. Primary outcome measures of this study were the association between MLE angle groups and the pain scores obtained by the SF-MPQ. Pain scores were evaluated both separately for each part of form (affective-sensory, VPS, and PPI scale) and totally. Beside to the primary pain score outcomes, the obstruction to daily activities, the need to analgesics at $24 \mathrm{~h}$ and 7 days postpartum were compared among groups. PPI and VPS scores were rearranged as low, moderate, and high pain according to obtained score point (for PPI 1 point, $2-3$ points and $4-5$ points; for VPS: $0-3$ points, $4-6$ points, and $7-10$ points, respectively). All outcomes were compared among three episiotomy angle groups.

Confounding variables that could affect perineal pain were defined as maternal age, body mass index (BMI), antenatal care, educational status, duration of second stage of labor, neonatal birth weight, and neonatal head circumference. The data of the confounding variables were obtained patients' medical records.

\section{Statistical Analysis}

Angle for MLE was measured continuously and categorized into three groups which are " $<40^{\circ}, 40^{\circ}-60^{\circ}$, and $>60^{\circ}$ " groups. Pain scores were measured with pain scales forms repetitively on both day 1 and day 7 . Correlations of the pain score among angle groups at the $1^{\text {st }}$ and $7^{\text {th }}$ days were tested by Spearman analysis. Correlation was found to be very weak, so days 1 and 7 were analyzed separately. In addition, the effect of angle on pain relief over time was analyzed by taking the differences of pain between day 1 and day 7. Whether each quantitative variable was distributed normally within the groups was determined according to Kolmogorov-Smirnov test, QQ and PP plots, and kurtosis and skewness values. As a result, the quantitative variables were summarized with median and IQR. The qualitative variables were summarized by frequencies and percentages and described using contingency tables. Density plots were examined to see whether the shape distribution of the quantitative variables in each angle group was the same. For the variables with similar distributions within each group, KruskalWallis test was used to compare the medians; otherwise, one-way analysis of variance with permutation test was 
TABLE 1. Baseline characteristics of the study population according to different mediolateral episiotomy angle

\begin{tabular}{|c|c|c|c|c|}
\hline Characteristics & $\begin{array}{c}\text { Group 1 } \\
\left(<40^{\circ}\right)(n=30)\end{array}$ & $\begin{array}{c}\text { Group } 2 \\
\left(40-60^{\circ}\right)(n=38)\end{array}$ & $\begin{array}{c}\text { Group 3 } \\
\left(\geq 60^{\circ}\right)(n=18)\end{array}$ & $p^{9}$ \\
\hline Quantitative & Med; IQR (Min-Max) & Med; IQR (Min-Max) & Med; IQR (Min-Max) & \\
\hline Age (year) & $24 ; 7(18-35)$ & $25 ; 8.75(18-38)$ & $25 ; 5.5(20-35)$ & 0.600 \\
\hline Maternal weight (kg) & $71 ; 5.75(67-86)$ & $72.5 ; 7(65-84)$ & $70 ; 4.25(67-82)$ & 0.367 \\
\hline BMI & $28.1 ; 2.13(24.6-33.6)$ & $27.65 ; 2.23(23.5-32.8)$ & $27.55 ; 1.55(25.5-32)$ & 0.601 \\
\hline "e" length (cm) & $45 ; 10^{\mathrm{a}}(30-60)$ & $40 ; 11.25^{b}(25-60)$ & $37.5 ; 10^{\mathrm{b}}(30-50)$ & $0.002^{*}$ \\
\hline "a" length (cm) & $40 ; 7.5(30-55)$ & $40 ; 10(20-60)$ & $40 ; 10(30-45)$ & 0.284 \\
\hline "c" length(cm) & $25 ; 10^{\mathrm{a}}(20-35)$ & $30 ; 5^{\mathrm{b}}(20-40)$ & $40 ; 6.25^{c}(30-50)$ & $<0.001 *$ \\
\hline Head circumference $(\mathrm{cm})$ & $35.05 ; 0.8(32.6-37.4)$ & $35 ; 1.28(32.8-37.3)$ & $34.8 ; 2.05(33.2-36.7)$ & 0.459 \\
\hline Birth week & $39 ; 2(37-41)$ & $39 ; 2$ (37-41) & $39 ; 2.25(37-40)$ & 0.690 \\
\hline Birth weight (g) & $3055 ; 735$ (2280-4040) & $3270 ; 537(2360-4370)$ & $3095 ; 860(2450-3910)$ & 0.3 \\
\hline $2^{\text {nd }}$ stage of delivery ( $\min$ ) & $30 ; 20(10-80)$ & $20 ; 15(10-60)$ & $25 ; 13.7(15-50)$ & 0.07 \\
\hline Qualitative & $\%$ & $\%$ & $\%$ & $p^{\text {भा? }}$ \\
\hline Education status & & & & 0.1 \\
\hline Elementary & 36 & 36 & 29 & \\
\hline Vocational & 29 & 54 & 17 & \\
\hline High school & 45 & 42 & 13 & \\
\hline College/university & 17 & 17 & 67 & \\
\hline Antenatal care & & & & 0.7 \\
\hline No & 28 & 48 & 24 & \\
\hline Yes & 38 & 43 & 20 & \\
\hline Analgesics & & & & 0.09 \\
\hline No & 83 & 17 & 0 & \\
\hline Paracetamol & 25 & 47 & 28 & \\
\hline Diclofenac sodium & 30 & 70 & 0 & \\
\hline Paracetamol and diclofenac & 37 & 39 & 24 & \\
\hline
\end{tabular}

Med: Median; IQR: Inter quartile range; Min-Max: Minimum-maximum; BMI: Body mass index; "e": Distance directed from the posterior fourchette to the lowest tip of episiotomy; "a": A length measured from the posterior fourchette to the anal canal; " $c$ ": A length measured from the lowest tip of episiotomy to the anal canal; $\uparrow$ : $P$ value was calculated using Kruskal-Wallis test; १ף: $P$ value calculated using Fisher's exact test; *: P<0.05; Post hoc test results are shown in the table with superscript letters. The groups with same letter are not significantly different.

used. The "ad.test" function in "kSamples" package was used to perform Anderson-Darling test to check for equality of distributions within each group for each variable. For the variables, which were statistically significant between groups, pairwise comparisons were performed using Bonferroni correction. Fisher's exact test was used for qualitative variables. $R$ software 3.6 program was used for analyses. One-way analysis of variance with permutation test was conducted using the "independence test" function in the "coin" package, and for pairwise permutation test "rcompanion" package was employed. $\mathrm{P}<0.05$ was considered statistically significant.

\section{RESULTS}

A total of 86 eligible women were allocated in this study; 30 of them were in Group 1; 38 women were in Group 2; and 18 of them were in Group 3. The range of participants' age varied from 18 to 35 years, with 24 years median. Median maternal weight was found $71 \mathrm{~kg}$. The maternal age, weight, and BMI did not show any significantly difference among the study groups (Table 1).

Length of episiotomy line was found significantly different among the groups. Group 1 had the longest 
TABLE2. Perineal pain assessment and need to analgesic at postpartum day 1 and day 7

\begin{tabular}{|c|c|c|c|c|}
\hline Characteristics & $\begin{array}{c}\text { Group 1 } \\
\left(<40^{\circ}\right)(n=30)\end{array}$ & $\begin{array}{c}\text { Group } 2 \\
\left(40-60^{\circ}\right)(n=38)\end{array}$ & $\begin{array}{c}\text { Group 3 } \\
\left(\geq 60^{\circ}\right)(n=18)\end{array}$ & $\mathrm{p}$ \\
\hline SF-MPQ & Med; IQR (Min-Max) & Med; IQR (Min-Max) & Med; IQR (Min-Max) & \\
\hline Sensory pain score day 1 & $2 ; 1(1-8)$ & $2 ; 0(1-7)$ & $2 ; 0.25(1-3)$ & $0.866^{\natural}$ \\
\hline Sensory pain score days 7 & $0 ; 1(0-2)^{a}$ & $0 ; 0(0-1)^{b}$ & $0 ; 0.25(0-1) a^{b}$ & $0.002^{111, *}$ \\
\hline VPS day 1 & $2 ; 1.25(1-4)$ & $3 ; 1.25(1-5)$ & $3 ; 1.25(1-4)$ & $0.956 \rrbracket$ \\
\hline VPS days 7 & $0 ; 2(0-2)^{a}$ & $0 ; 0(0-2)^{\mathrm{b}}$ & $0 ; 0.25(0-2)^{\mathrm{ab}}$ & $0.003^{19, *}$ \\
\hline PPI day 1 & $2 ; 0(1-4)$ & $2 ; 0(1-4)$ & $2 ; 1(1-3)$ & $0.274 \uparrow$ \\
\hline PPI days 7 & $0 ; 0.25(0-1)^{a}$ & $0 ; 0(0-1)^{\mathrm{b}}$ & $0 ; 0.25(0-1)^{\mathrm{ab}}$ & $0.027^{119, *}$ \\
\hline Total pain score \# day 1 & $7 ; 3(4-21)$ & $8 ; 2.7(4-17)$ & $8 ; 1(4-11)$ & $1^{9}$ \\
\hline Total pain score & $6.5 ; 3.5(2-21)$ & $8 ; 2.75(3-17)$ & $8 ; 3(2-11)$ & 0.06 \\
\hline VPS pain score & $2 ; 2(0-4)$ & $2.5 ; 2(0-5)$ & $2 ; 2(0-4)$ & 0.6 \\
\hline PPI pain score & $2 ; 1(1-4)$ & $2 ; 0(1-4)$ & $1.5 ; 1(0-3)$ & 0.1 \\
\hline
\end{tabular}

SF-MPQ: Short-form McGill pain questionnaire; Med: Median; IQR: Inter quartile range; Min-Max: Minimum-maximum; VPS: Visual pain scale; PPI: Present pain intensity scale; १: P value was calculated using Kruskal-Wallis test; ११: $\mathrm{P}$ value calculated using one-way analysis with permutation test; $*$ : P<0.05; a,b, ab: Post hoc test results are shown in the table with letters. The groups with same letter are not significantly different. \#: Total pain score represents a total score obtained by parts of SF-MPQ (sensory-affective, VPS, and PPI).

median episiotomy length with $45 \mathrm{~mm}$ and there was a statistically significant difference between the each other group $(p<0.002)$. The median lengths of distance from the lowest tip of episiotomy to the anal canal (" $c$ " line) were found $40 \mathrm{~mm}$ in Group 3, $30 \mathrm{~mm}$ in Group 2 , and $25 \mathrm{~mm}$ in Group 1. There were significant differences among groups $(\mathrm{p}<0.001)$. At the birth; gestational week, weight, and head circumference of newborn did not show any statistical significance among the groups. Second stage of delivery, with $30 \mathrm{~min}$, in Group 1 was found markedly long compare with the other groups, but there was no statistical significance among the groups. Maternal educational status, antenatal care during pregnancy period, and the types of analgesic prescribed were not found statistically significant among the groups. The results are presented in Table 1.

There were no significant differences among the three groups in terms of the total pain scores on the SF-MPQ and the pain score of each part of form (i.e., VPS, PPI, sensory, and affective) at the postpartum $1^{\text {st }}$ day. At 7 days postpartum, the pain scores obtained from the overall of questionnaire form and each part of form were high in the Group 1 compare with the other groups. A significant difference was found between the Group 1 and the Group 2 in terms of pain scores (Table 2). The change of pain score between day 1 and day 7 was not found significant among groups.

Pain with daily activities did not show any difference among groups at $24 \mathrm{~h}$ and on postpartum day 7 . The need to analgesics was high in Group 2 at $24 \mathrm{~h}$ after delivery, but the difference was not found significant among groups. At 7 days postpartum, the need to analgesic was significantly high in the Group 1 compare with Group 2 (Table 3).

The length of " $c$ " line was found significantly more long in the PPI: 1 point pain score group than the PPI: $2-3$ point groups. Birth week was significantly short in the PPI: 1 point group than the PPI: $2-3$ point groups. The other variables did not show significant difference among the PPI pain groups. The results are presented in Table 4.

Seventy-three women (85\%) scored the perineal pain between 0 and 3 on the VPS and 13 women (15\%) rated 
TABLE 3. Analysis of pain with daily activities and need to analgesic in three angle groups on day 1 and on day 7

\begin{tabular}{lcccc} 
Characteristics & $\begin{array}{c}\text { Group 1 } \\
\left(<40^{\circ}\right)(\mathrm{n}=30)\end{array}$ & $\begin{array}{c}\text { Group 2 } \\
\left(40-60^{\circ}\right)(\mathrm{n}=38)\end{array}$ & $\begin{array}{c}\text { Group 3 } \\
\left(\geq 60^{\circ}\right)(\mathrm{n}=18)\end{array}$ & $\mathrm{p}^{\natural}$ \\
\hline SF-MPQ & Med; IQR (Min-Max) & Med; IQR (Min-Max) & Med; IQR (Min-Max) \\
\hline Pain with daily activities (yes) (\%) & & & & \\
$\quad$ Pain on defecation day 1 & $25(33.8)$ & $33(44.6)$ & $16(21.6)$ & 0.851 \\
Pain on defecation days 7 & $28(34.1)$ & $36(43.9)$ & $18(22)$ & 0.821 \\
Pain on sitting day 1 & $19(31.7)$ & $29(48.3)$ & $12(20)$ & 0.465 \\
Pain on sitting days 7 & $17(26.2)$ & $34(52.3)$ & $14(21.5)$ & 0.07 \\
Pain on moving day 1 & $24(34.3)$ & $32(45.7)$ & $14(20)$ & 0.821 \\
Pain on moving days 7 & $26(32.5)$ & $36(45)$ & $16(22.5)$ & 0.292 \\
Pain on sleeping day 1 & $26(33.3)$ & $36(46.2)$ & $18(22.2)$ & 0.498 \\
Pain on sleeping days 7 & $26(32.1)$ & $37(45.79)$ & $18(22.5)$ & 0.140 \\
Need to analgesic day 1 & $25(31.3)$ & $37(46.3)$ & $14(25)^{\mathrm{ab}}$ & 0.056 \\
Need to analgesic days 7 & $24(42.9)^{\mathrm{a}}$ & $18(31.2)^{\mathrm{b}}$ & $\mathbf{0 . 0 1 2}$ \\
\hline
\end{tabular}

ף: $P$ value calculated using Fisher's exact test; $*: P<0.05 ; a, b$, ab: Post hoc test results are shown in the table with letters. The groups with same letter are not significantly different.

the range from 4 to 6 . No participant scored to pain the range between 7 and 10. Because of that, the range VPS score 7-10 was cancelled and comparison was done between two VPS score groups (Table 5).

\section{DISCUSSION}

The current study is the first prospective study evaluating the postpartum perineal pain among the MLE angle intervals. We have demonstrated that all of women in this study experienced perineal pain at the $1^{\text {st }}$ day postpartum regardless of episiotomy angle. Ninety-three percent of them required analgesia. At 7 days postpartum, women with the MLE angle close to the perineal midline with $<40^{\circ}$ had more pain score than women who had MLE angle with $40-60^{\circ}$ for all pain measurement instruments. Considering the differences between angle of episiotomy after primary repair and scar angle, to perform MLE with more acute angle than $40^{\circ}$ makes episiotomy incision closer to the anal sphincter and epithelium [19-21]. Even more it is claimed that an angle about $30^{\circ}$ or less is likely to function like a midline incision [15]. Therefore, inflammatory area surrounding the incision with angle $<40^{\circ}$ might apply more compression on the nerve branches supplying anal region compare with the other angle range, and cause much more pain on postpartum day 7 .
Although, there is general agreement about restricting use of episiotomy, it is still the most frequent surgical procedure in daily obstetric routine. In the worldwide, episiotomy rates in the primiparous vary from $63.3 \%$ to $100 \%$ [22]. From Turkey, the rates for primiparous are reported in the range from $43.1 \%$ to $95 \%[23,24]$.

The relationship between the episiotomy type and the perineal pain has been well researched issue [25, $26]$. There are scarcely data about the relationship between MLE angle and postpartum perineal pain [19]. Considering the lack of studies evaluating MLE, the only one similar to the present study is a prospective investigation conducted by El-Din et al [19]. They have reported that the rate of patient with moderate/severe episiotomy-related pain at $24 \mathrm{~h}$ postpartum was significantly higher in the $60^{\circ}$-angled MLE group compare with $40^{\circ}$-angled ones [19].

In this study, we found significant difference in terms of pain scores between women with MLE angle $<40^{\circ}$ and $40-60^{\circ}$ at 7 days postpartum. We did not find any difference among groups in terms of episiotomy related pain at the postpartum $24 \mathrm{~h}$ as inconsistency with reported by El-Din et al [19]. Inclusion criteria of the study might be one of the causes of this mismatch. They included in their study the patient with perineal tears, while we excluded them. The other reason of this conflict may be 
TABLE 4. Comparisons of properties of three present pain intensity categories of perineal pain at the $1^{\text {st }}$ postpartum day

Characteristics

PPI scores

$p^{n}$

Point: $1(n=19) \quad$ Point: $2-3(n=56) \quad$ Point: $4-5(n=11)$

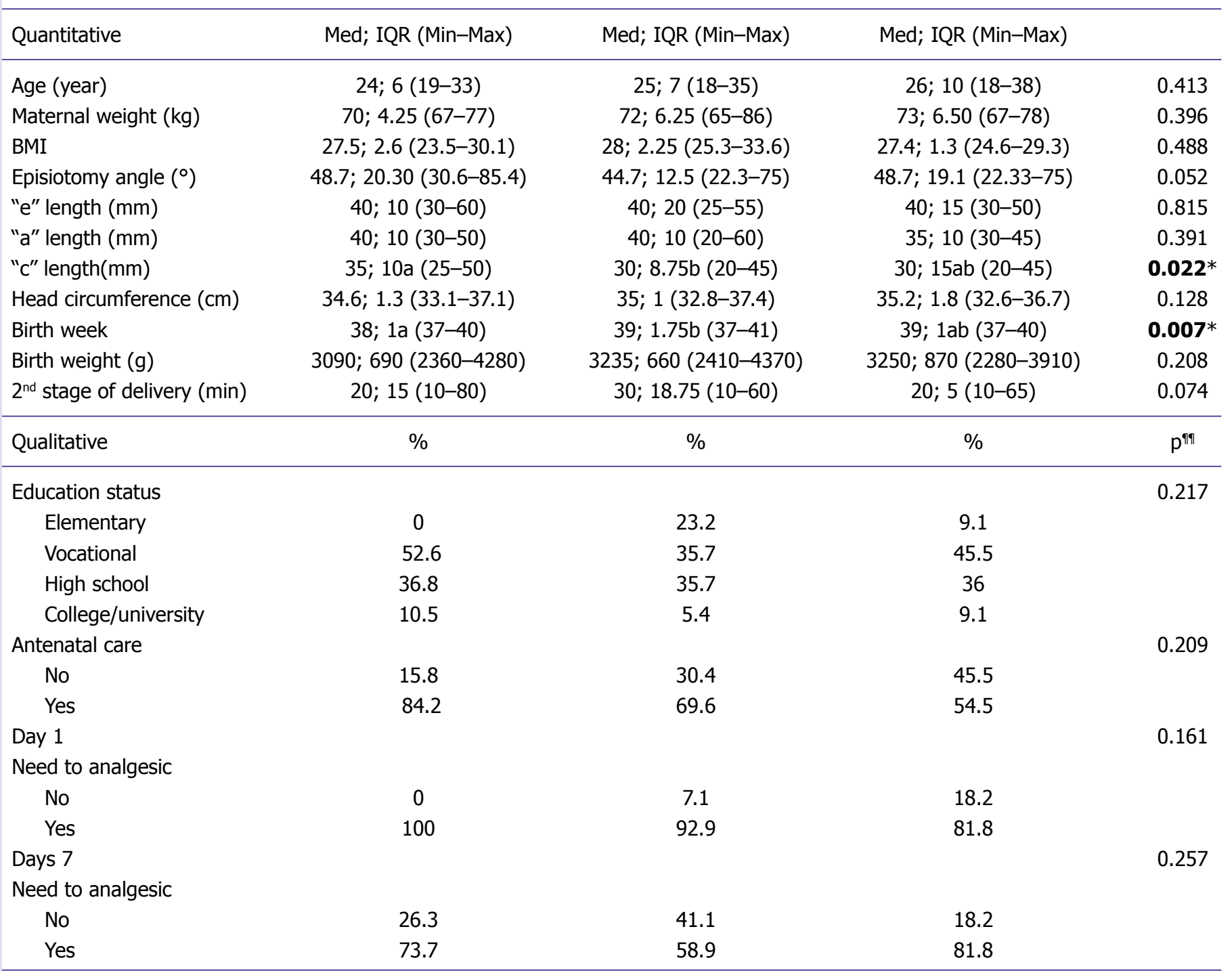

Med: Median; IQR: Inter quartile range; Min-Max: Minimum-maximum; BMI: Body mass index; "e" length: Distance directed from the posterior fourchette to the lowest tip of episiotomy; "a" length: A length measured from the posterior fourchette to the anal canal; " $c$ " length: A length measured from the lowest tip of episiotomy to the anal canal; १: P value was calculated using Kruskal-Wallis test; ११: P value calculated using Fisher's exact test; *: P<0.05; a,b ,ab: Post hoc test results are shown in the table with letters. The groups with same letter are not significantly different.

the measurement method of episiotomy related pain. They evaluated perineal pain using a verbal rating scale and classifying pain as no/moderate/severe. We measured pain with score using MC-Gill pain questionnaire short form, VPS and PPI scale. Therefore, we evaluated postpartum perineal pain using both unidimensional and multidimensional instruments. There are limited numbers of pain measurement instruments which are quantifiable, reliable, and valid. The SF-MPQ is the multidimensional instrument. Its reliability and validity are classified as good. It consists of the sensory and affective dimensions of pain and also two parts (VPS and PPI) assessing intensity of pain. The VPS and PPI scales are unidimensional instruments [27]. Unidimensional scales 
TABLE 5. Comparison of maternal and neonatal properties between two visual pain scale categories of perineal pain at the $1^{\text {st }}$ postpartum day

Characteristics

Visual pain scale scores

$p^{n}$

$0-3(n=73) \quad 4-6(n=13)$

\begin{tabular}{|c|c|c|c|}
\hline Quantitative & Med; IQR (Min-Max) & Med; IQR (Min-Max) & \\
\hline Age (year) & $25 ; 8(18-38)$ & $24 ; 5(20-33)$ & 0.582 \\
\hline Maternal weight $(\mathrm{kg})$ & $71 ; 21(65-86)$ & $70 ; 8.25(67-81)$ & 0.787 \\
\hline BMI & $27.8 ; 1.95(23.5-33.6)$ & $28 ; 2.2(24.6-31.6)$ & 0.579 \\
\hline Episiotomy angle $\left(^{\circ}\right)$ & $48.7 ; 14.4(23-85.4)$ & $39 ; 21.6(22.3-79)$ & 0.066 \\
\hline "e" length (mm) & $40 ; 15(25-60)$ & $45 ; 10(30-50)$ & $0.033 *$ \\
\hline "a" length (mm) & $40 ; 10(20-60)$ & $40 ; 10(30-45)$ & 0.776 \\
\hline "c" length(mm) & $30 ; 5(20-50)$ & $30 ; 15(20-45)$ & 0.199 \\
\hline Head circumference $(\mathrm{cm})$ & $35 ; 1.25(32.8-37.4)$ & $35.1 ; 1.1(32.6-36)$ & 0.767 \\
\hline Birth week & $39 ; 2$ (37-41) & $39 ; 2(37-40)$ & 0.950 \\
\hline Birth weight $(\mathrm{g})$ & $3170 ; 680(2360-4370)$ & $3100 ; 615(2280-3810)$ & 0.596 \\
\hline $2^{\text {nd }}$ stage of delivery $(\mathrm{min})$ & $25 ; 15(10-80)$ & $25 ; 15(15-65)$ & 0.908 \\
\hline Qualitative & $\%$ & $\%$ & $p^{\text {กा }}$ \\
\hline Education status & & & 0.933 \\
\hline Elementary & 16.4 & 15.4 & \\
\hline Vocational & 39.7 & 46.2 & \\
\hline High school & 35.6 & 38.5 & \\
\hline College/university & 8.2 & 0 & \\
\hline Antenatal care & & & 0.510 \\
\hline No & 27.4 & 38.5 & \\
\hline Yes & 72.6 & 61.5 & \\
\hline Day 1 & & & 0.223 \\
\hline \multicolumn{4}{|l|}{ Need to analgesic } \\
\hline No & 5.5 & 15.4 & \\
\hline Yes & 94.5 & 18.6 & \\
\hline Days 7 & & & 0.529 \\
\hline \multicolumn{4}{|l|}{ Need to analgesic } \\
\hline No & 37 & 23.1 & \\
\hline Yes & 63 & 76.9 & \\
\hline
\end{tabular}

Med: Median; IQR: Inter quartile range; Min-Max: Minimum-maximum; BMI: Body mass index; " $e$ " length: Distance directed from the posterior fourchette to the lowest tip of episiotomy; "a" length: A length measured from the posterior fourchette to the anal canal; " $\mathrm{c}$ " length: A length measured from the lowest tip of episiotomy to the anal canal. १: P value was calculated using Mann-Whitney U-test; ११: P value calculated using Fisher's exact test; *: P<0.05.

are suggested to measure acute pain caused by trauma, surgery, childbirth, or an acute medical disease [28, 29].

Standard incision angle for MLE is defined as an angle beginning from the posterior fourchette and directed laterally downward away from the rectum with $40^{\circ}-60^{\circ}$ [16]. Even though well-defined angle direction, it has been performed with a tendency toward incisions with too acute angles $\left(<30^{\circ}\right)[30]$ and has showed inter indi- vidual differences in practical application [20]. Considering of the consequences of these researches, we grouped the episiotomy angle in a range, not at a point and allocated women to the angle range groups as $<40^{\circ}$, between 40 and $60^{\circ}$, equal or more than $60^{\circ}$. In the previous study reported by El-Din et al. [19], episiotomy angle has been evaluated at the specific angle point (i.e., $40^{\circ}$ and $60^{\circ}$ ) and participants allocated to this angle group. Another 
reason of inconsistency may be difference of defining of groups in the previous and current study.

In the present study, $85 \%$ of women with MLE rated their pain between 0 and 3 on the VPS (range 0-10) and $15 \%$ of all women scored their perineal pain at the range from 4 to 6 at $24 \mathrm{~h}$ postpartum. There were no women scored the perineal pain higher than 7 with VPS. Karbanova et al. [25] reported that 29 (10.9\%) of women with MLE rated their pain as 7-10 using the same scoring system. Fodstad et al. [31] reported that 23\% of women with MLE rated their pain between 7 and 10 on the VAS. Most women rated their pain low (0-3) or moderate (4-6) with VAS, 50 and $27 \%$, respectively.

We did not find any difference among groups for pain with daily activities on postpartum day 1 and day 7 . Andrews et al. [2] have been reported that perineal pain with daily activities was significantly high in the women with uncomplicated MLE compared to women with spontaneous second-degree tear on day 5 after delivery. At day 1 , they did not find any significant differences in pain scores at rest, sitting, or moving between these two groups.

At the postpartum period, most women require analgesics. Perineal pain is transmitted through motor, sensory, and autonomic fibers of the pudendal nerve. Episiotomy is an iatrogenic injury for pudendal nerve because of cutting of nerve fibers. The inflammation, hematoma, and suture materials in the wound area create compression effect on nerve branches and cause perineal pain. Analgesics can reduce the nociceptive response to inflammatory mediators arising from local trauma. In this study, we found that, the requirement to analgesic was $93 \%$ for all women at the $1^{\text {st }}$ day. It was $65 \%$ for overall women on days 7 and significantly high in the women Group 1 with $42.9 \%$ compare with group 2 with $31.2 \%$. Karbanova et al. [25] reported that number of women using analgesics in the $24 \mathrm{~h}$ were $38(14.3 \%)$ in women with MLE.

We found that overall length of episiotomy line was 40 $\mathrm{mm}$ in $25-60 \mathrm{~mm}$ range. This was reported $37 \mathrm{~mm}$ with $30-42 \mathrm{~mm}$ range by Karbanova et al. [25]. In our study, the median episiotomy length of MLE was $37.5 \mathrm{~mm}$ (min$\max =30-50 \mathrm{~mm}$ ) for the group with angle $\geq 60^{\circ}$ and 45 $\mathrm{mm}(\mathrm{min}-\mathrm{max}=30-60 \mathrm{~mm}$ ) for the group with angle $<40^{\circ}(\mathrm{p}=0.002)$. 19. El-Din et al. [19] (2014) found that mean MLE length was $41 \mathrm{~mm}(\min -\max =28-56 \mathrm{~mm})$ in the $60^{\circ}$-angled group and $38 \mathrm{~mm}(\min -\max =20-55$ $\mathrm{mm})$ in the $40^{\circ}$-angled group $(\mathrm{p}=0.001)$.

Protection against obstetric anal sphincter injuries is the potential effect of MLE. Optimal angle required for the protective effect of MLE has been reported as an angle of at least $40^{\circ}[30,32-34]$. MLE applied with angles that are too narrow and close to the midline are associated with a higher risk of uncontrolled obstetric anal sphincter injuries. Current study showed that the MLE angled more acute than $40^{\circ}$ has the critical value for perineal pain on postpartum day 7 .

The strengths of this study were its prospective design, analysis of primiparous women with no previously incised perineum and no current tear perineum, and the measurements of perineal pain in the different angles range. The women completed the questionnaires both on days 1 and on days 7 were included in the study. Our including criteria limited the number of patients. Hence, the study had the relatively small number of patients, even though the power was sufficient. The relatively short data collection period might be effect number of participants. MLE was performed by trained assistant doctors under supervision of senior specialist obstetricians but measuring of the MLE angle and interrogating of patients' pain were applied by just two researchers. The number of participants included in the study was also restricted by limited number researchers who they were responsible the measurement of all study parameter. Larger prospective studies are needed to investigate the correlation between the MLE angle ranges and the long-term effect on the perineal pain, sexual disfunction, and dyspareunia.

\section{Conclusion}

There is scarcely knowledge in literature about the relationship between MLE angle and perineal pain intensity. In this study, we focused on relationship between the MLE angle in the certain range and the perineal pain in the early postpartum period. We aimed to find out whether there is angle related with the postpartum perineal pain. We demonstrated that MLE angles that are too narrow and close to the midline are associated with a higher score of perineal pain. We suggest to avoid performing MLE with $<40^{\circ}$ so that women experience less perineal pain at the early postpartum period.

Ethics Committee Approval: Istanbul Medeniyet University Goztepe Training and Research Hospital Ethics Committee granted approval for this study (date: 20.03.2012, number: 20/L).

Conflict of Interest: No conflict of interest was declared by the authors.

Financial Disclosure: The authors declared that this study has received no financial support. 
Authorship Contributions: Concept - HB; Design - HB, DD; Supervision - HB; Fundings - HB, MH; Materials - HB; Data collection and/ or processing - $\mathrm{HB}, \mathrm{DD}$; Analysis and/or interpretation - $\mathrm{HB}$, EA; Literature review - HB, DD; Writing - HB, EAs; Critical review - HB, EA.

\section{REFERENCES}

1. World Health Organization. Protecting, promoting and supporting breastfeeding in facilities providing maternity and new born services. Available at: https://www.who.int/nutrition/publications/guidelines/breastfeeding-facilities-maternity-newborn/en/. Accessed Feb 5, 2021.

2. Andrews V, Thakar R, Sultan AH, Jones PW. Evaluation of postpartum perineal pain and dyspareunia-a prospective study. Eur J Obstet Gynecol Reprod Biol 2008;137:152-6. [CrossRef]

3. Macarthur AJ, Macarthur C. Incidence, severity, and determinants of perineal pain after vaginal delivery: a prospective cohort study. Am J Obstet Gynecol 2004;191:1199-204. [CrossRef]

4. Carroli G, Belizan J, Stamp G. Episiotomy for vaginal birth. Birth 1999;26:263. [CrossRef]

5. Swenson CW, DePorre JA, Haefner JK, Berger MB, Fenner DE. Postpartum depression screening and pelvic floor symptoms among women referred to a specialty postpartum perineal clinic. Am J Obstet Gynecol 2018;218:335.e1-335.e6. [CrossRef]

6. Kettle C, Hills RK, Ismail KM. Continuous versus interrupted sutures for repair of episiotomy or second degree tears. Cochrane Database Syst Rev 2007:CD000947. [CrossRef]

7. Kalis V, Laine K, de Leeuw JW, Ismail KM, Tincello DG. Classification of episiotomy: towards a standardisation of terminology. BJOG 2012;119:522-6. [CrossRef]

8. Shojae KK, Dawati A, Zayeri F. Frequency and side effect of episiotomy in primiparous women: a three-month longitudinal survey. Qom Univ Med Sci J 2009;3:47-50.

9. Lam KW, Wong HS, Pun TC. The practice of episiotomy in public hospitals in Hong Kong. Hong Kong Med J 2006;12:94-8.

10. Carroli G, Mignini L. Episiotomy for vaginal birth. Cochrane Database Syst Rev 2009:CD000081. [CrossRef]

11. Chou D, Abalos E, Gyte GM, Gülmezoglu AM. Paracetamol/acetaminophen (single administration) for perineal pain in the early postpartum period. Cochrane Database Syst Rev 2010:CD008407. [CrossRef]

12. Senol DK, Aslan E. The Effects of Cold Application to the Perineum on Pain Relief After Vaginal Birth. Asian Nurs Res (Korean Soc Nurs Sci) 2017;11:276-82. [CrossRef]

13. Karaçam Z, Ekmen H, Calişir $H$. The use of perineal massage in the second stage of labor and follow-up of postpartum perineal outcomes. Health Care Women Int 2012;33:697-718. [CrossRef]

14. Jordan J. Topical NSAIDs for acute musculoskeletal pain in adults. Am Fam Physician 2016;94.

15. Tincello DG, Williams A, Fowler GE, Adams EJ, Richmond DH, Alfirevic Z. Differences in episiotomy technique between midwives and doctors. BJOG 2003;110:1041-4. [CrossRef]
16. Andrews V, Thakar R, Sultan AH, Jones PW. Are mediolateral episiotomies actually mediolateral? BJOG 2005;112:1156-8. [CrossRef]

17. Melzack R. The McGill Pain Questionnaire: major properties and scoring methods. Pain 1975;1:277-99. [CrossRef]

18. Jensen MP, Karoly P, Braver S. The measurement of clinical pain intensity: a comparison of six methods. Pain 1986;27:117-26. [CrossRef]

19. El-Din AS, Kamal MM, Amin MA. Comparison between two incision angles of mediolateral episiotomy in primiparous women: a randomized controlled trial. J Obstet Gynaecol Res 2014;40:1877-82. [CrossRef]

20. Kalis V, Karbanova J, Horak M, Lobovsky L, Kralickova M, Rokyta Z. The incision angle of mediolateral episiotomy before delivery and after repair. Int J Gynaecol Obstet 2008;103:5-8. [CrossRef]

21. Kalis V, Landsmanova J, Bednarova B, Karbanova J, Laine K, Rokyta $Z$. Evaluation of the incision angle of mediolateral episiotomy at $60 \mathrm{de}$ grees. Int J Gynaecol Obstet 2011;112:220-4. [CrossRef]

22. Graham ID, Carroli G, Davies C, Medves JM. Episiotomy rates around the world: an update. Birth 2005;32:219-23. [CrossRef]

23. Kütük MS, Dolanbay M, Özgün MT, Özdemir F, Öztürk A, Aygen E. Retrospective analysis of episiotomy rate in Erciyes University. Gynecol Obstet Reprod Med 2014;20:10-4.

24. Karaçam Z, Eroğlu K. Effects of episiotomy on bonding and mothers' health. J Adv Nurs 2003;43:384-94. [CrossRef]

25. Karbanova J, Rusavy Z, Betincova L, Jansova M, Necesalova P, Kalis $\mathrm{V}$. Clinical evaluation of early postpartum pain and healing outcomes after mediolateral versus lateral episiotomy. Int J Gynaecol Obstet 2014;127:152-6. [CrossRef]

26. Ginath S, Elyashiv O, Weiner E, Sagiv R, Bar J, Menczer J, et al. The optimal angle of the mediolateral episiotomy at crowning of the head during labor. Int Urogynecol J 2017;28:1795-9. [CrossRef]

27. Flaherty SA. Pain measurement tools for clinical practice and research. AANA J 1996;64:133-40.

28. Breivik H, Borchgrevink PC, Allen SM, Rosseland LA, Romundstad L, Hals EK, et al. Assessment of pain. Br J Anaesth 2008;101:17-24.

29. Bech RD, Lauritsen J, Ovesen O, Overgaard S. The Verbal Rating Scale Is Reliable for Assessment of Postoperative Pain in Hip Fracture Patients. Pain Res Treat 2015;2015:676212. [CrossRef]

30. Eogan M, Daly L, O'Connell PR, O'Herlihy C. Does the angle of episiotomy affect the incidence of anal sphincter injury? BJOG 2006;113:190-4. [CrossRef]

31. Fodstad K, Laine K, Staff AC. Different episiotomy techniques, postpartum perineal pain, and blood loss: an observational study. Int Urogynecol J 2013;24:865-72. [CrossRef]

32. Stedenfeldt M, Pirhonen J, Blix E, Wilsgaard T, Vonen B, Øian P. Episiotomy characteristics and risks for obstetric anal sphincter injuries: a case-control study. BJOG 2012;119:724-30. [CrossRef]

33. Andrews V, Sultan AH, Thakar R, Jones PW. Risk factors for obstetric anal sphincter injury: a prospective study. Birth 2006;33:117-22.

34. van Dillen J, Spaans M, van Keijsteren W, van Dillen M, Vredevoogd $C$, van Huizen $M$, et al. A prospective multicenter audit of labor-room episiotomy and anal sphincter injury assessment in the Netherlands. Int J Gynaecol Obstet 2010;108:97-100. [CrossRef] 